\title{
Latex Glove Samples Cutting System with Rotary Cutter Mechanism
}

\author{
JL Tan, KS Sim, CK Toa
}

\begin{abstract}
In this study, it involves the protein determination of latex gloves for latex glove manufacturing industry. Natural rubber latex (NRL) gloves provide tactile properties, barrier protection, tear resistance, economy and comfort touch surface area which preferred by the medical field. However, there are more than 200 proteins in the NRL and 13 of them which are known to be allergens to human. In the manufacturing process of latex gloves, the Bradford reagent protein test method is used as a standard method for assessing protein levels for quality control. The current standard methods typically involve many procedures that manually operate which results in high processing time. Thus, new innovative design is needed and involved the cutting system that allows samples stamping and retrieved with less time consumption. The cutting machine can perform the automatic cutting of latex glove into several samples According to the current method, samples cutting process conducted by humans. Therefore, the new system is automated, which may only require an operator to place the glove at the input of the system and remove it at the end of the process. The new latex glove samples cutting system consists of Computer Numerical Control (CNC) moving mechanism with a $28 \mathrm{~mm}$ rotating rotary cutter as cutting die. Thus, the cutting system is able to shorten the processing time on protein determination.
\end{abstract}

Index Terms - Automated system, Cutting system, Latex glove, Protein detection.

\section{INTRODUCTION}

Widely applied natural rubber latex (NRL) gloves may consist of excess protein concentration that can cause allergic asthma latex sensitization skin allergy reactions. According to the statistics from U.S. Occupational Safety and Health Administration show that approximately $8 \%$ to $12 \%$ of health-care worker exhibit some form of allergy problem with less than $1 \%$ of the general population [1]. Thus, tracing the protein concentration is mandatory.

However, the Bradford reagent protein test method usually involves many processes and needs manually operate which will result in very time-consuming [2], [3]. In addition, sophisticated and bulky equipment such as spectrometer is required in order to perform the protein test. In the industries of latex glove manufacturers, they demand shorter processing time in order to improve their quality assurance (QA). Thus, this invention aims to provide an automated samples cutting system for protein concentration, shorten the processing time and lower the operation cost.

Revised Manuscript Received on August 14, 2019.

JL Tan, Faculty of Engineering and Technology, Multimedia Malaysia. (E-mail: tanjinlong95@ gmail.com)

KS Sim, Faculty of Engineering and Technology, Multimedia University, Jalan Ayer Keroh Lama, 75450 Bukit Beruang, Melaka, Malaysia. (E-mail: kssim@mmu.edu.my)

CK Toa, Faculty of Engineering and Technology, Multimedia University, Jalan Ayer Keroh Lama, 75450 Bukit Beruang, Melaka, Malaysia. (E-mail: toacheankhim@yahoo.com) University, Jalan Ayer Keroh Lama, 75450 Bukit Beruang, Melaka,

The whole protein determination process involves several machines such as the sample cutting, a chemical binding machine and a scanning mechanism. According to the current samples cutting method, the cutting process is conducted manually and involves variable preparation and factors, such as needed human to prepare different dimension template, the accuracy of samples location and the protein concentration preserves on the samples after the samples retrieved from the latex glove. Thus, the cutting system developed with automated and it does not require a lot of manpower. The operator only has to place the glove at the beginning of the system and remove it at the end of the process. Therefore, the automated samples cutting system is able to shorten the processing time.

The latex glove samples cutting system has two types of operating modes: Rotary Cutter Mode and Laser Cutter Mode. The rotary cutter mode operates with a rotary cutter as an actuator that consists of $28 \mathrm{~mm}$ diameter circular blade with degree single bevel design which increases the accuracy of slicing action. The actuator is able to perform $360^{\circ}$ degree rotations. It also allows the rotary cutter to be able to perform the cutting action with multiple-direction. The moving mechanism is controlled with Computer Numerical Control (CNC) design to increase the precision of the samples cutting process.

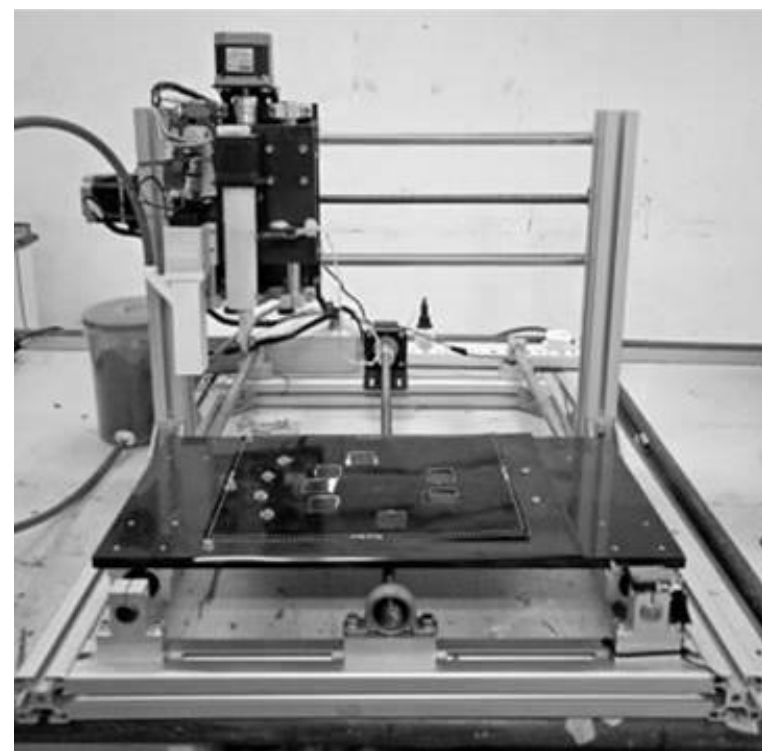

Fig. 1: Latex glove samples cutting system with a rotary cutter mechanism 


\section{LATEX GLOVE SAMPLES CUTTING SYSTEM WITH ROTARY CUTTER MECHANISM}

By the end of the project, this project able to help the QA process of latex glove especially institute who requires protein concentration analysis for latex gloves such as latex glove manufacturers, laboratories and Malaysia Rubber Board that conduct protein concentration test.

\section{MATERIAL AND DESIGN SELECTION FOR LATEX GLOVE CUTTING SYSTEM}

\section{A. Bradford reagent protein test}

In latex glove manufacturer, Bradford reagent protein test is used as quality assurance (QA) for protein detection on latex glove samples [4], [5]. Several procedures are involved in order to complete the protein detection test. The processes of the protein concentration test are shown as Fig. 2.

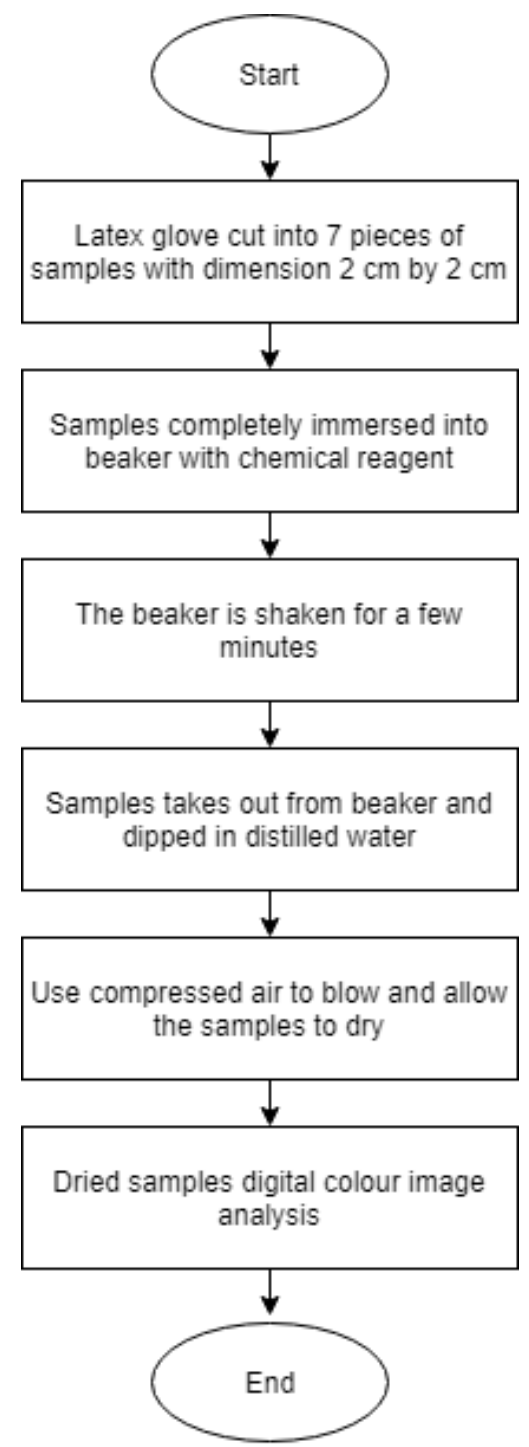

\section{Fig. 2: Flow chart of Bradford reagent protein test}

The procedures are categories into 2 categories, which are glove samples preparation and samples protein analysis. The glove samples preparation including samples cutting, samples chemical binding and samples image scanning. Currently, those processes are manually performed by humans and the cutting process usually took approximately 15 minutes in order to cut and obtain the samples with dimension $2 \mathrm{~cm}$ by $2 \mathrm{~cm}$. Thus, the latex glove samples cutting system with rotary cutter mechanism will involve as initial step of samples preparation.

\section{B. Design Flow}

The design flow chart in Fig. 3 shows the design tools and material data needs [6]. Each stage will need to collect information and analyses according to these aspects.

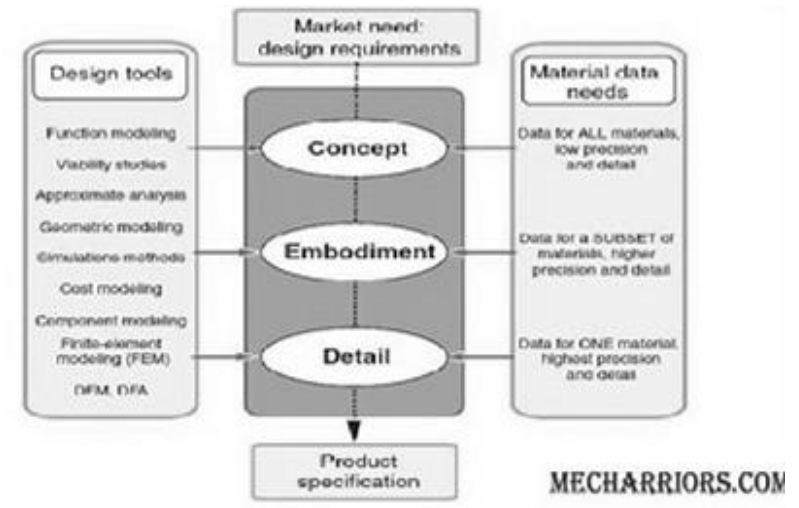

Fig. 3: Design flow chart

According to the design flow chart, materials have to be selected from different components of the latex glove samples cutting system including the research on materials properties and application.

\section{Cutting Tool Materials:}

Natural rubber latex glove has the characteristics of elastic and tears resistance. Thus, in order to cut the latex material, the cutting tool should have three characteristics [7] and is shown as table below:

Table I: The material characteristics

\begin{tabular}{|c|c|}
\hline Characteristic & Description \\
\hline Sharpness & Sharp edge and sharp bevel angle \\
\hline Wear resistance & $\begin{array}{c}\text { Able to perform several time of cutting } \\
\text { action, acceptable lifetime }\end{array}$ \\
\hline Toughness & $\begin{array}{c}\text { Tool would not fracture and withstand } \\
\text { minimum compressed force. }\end{array}$ \\
\hline
\end{tabular}

Therefore, the bevel of the cutting tool should be a single bevel knife edge with 15 to 17 degrees. The cutting edge with these characteristics suitable for the soft materials that are easier deformed by thermal stresses or thermal and provided a smooth cutting motion [8]. A rotary cutter with $28 \mathrm{~mm}$ diameter circular blade is able to cut the latex samples with a rotating blade movement, which increases of the lifetime and cutting surface area compare to carbon steel blades.

\section{Stress Components:}

When the cutting action performed, a compressed force will apply to the cutter. Therefore, a high tension spring is added on the top of the rotary cutter to reduce the damage of compressed force and increase the lifetime of the circular blade on the rotary cutter.

\section{Published By:}

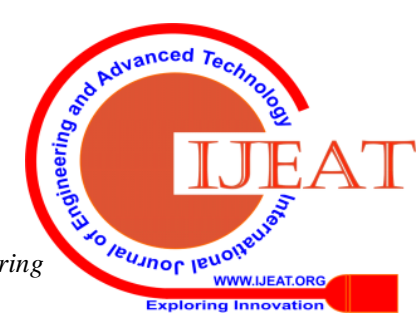


The moving mechanism of the latex glove samples cutting system is designed with Computer Numerical Control (CNC) mechanism. This design involved several components such as $12 \mathrm{~mm}$ diameter lead screw, $16 \mathrm{~mm}$ diameter stainless steel linear raft support, and linear bearing and NEMA 57 stepper motor. The lead screw controlled and rotate by turning the stepper motor, between these two components, a $6.35 \mathrm{~mm}$ to $12 \mathrm{~mm}$ Aluminum Stepper Flexible Resonance Damping Coupling is used in order to reduce the vibration that generates with moving action [9]. This flexible stepper motor coupling is shown in Fig. 4.

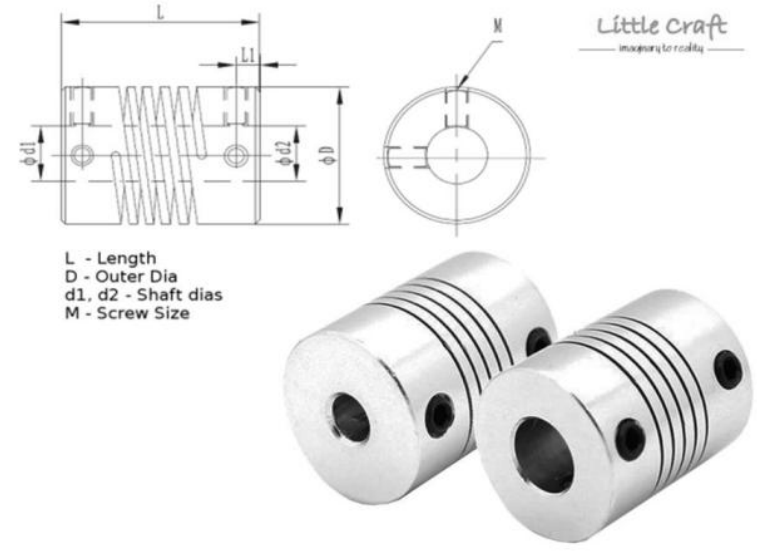

Fig. 4: Aluminum stepper flexible resonance damping coupling

\section{E. Structural Materials}

Due to multiple stepper motors are mounted on this latex glove samples cutting system with rotary cutter mechanism, vibration will generate while these stepper motors are rotating. Thus, the cutting system must have high stability, high strength and more compressive structure. $4 \mathrm{~cm}$ by $4 \mathrm{~cm}$ aluminium profiles is used as the materials for system structure which also widely used for aeronautical, marine and railway stock due to its low weight to high strength ratio [10].

\section{F. Hardened Steel}

A $16 \mathrm{~mm}$ diameter tough stainless steel linear guide rail support is used as the side guide and motion support for computer numerical control mechanism. The CNC design with stainless steel linear guide rail support is shown in Fig. 5 .

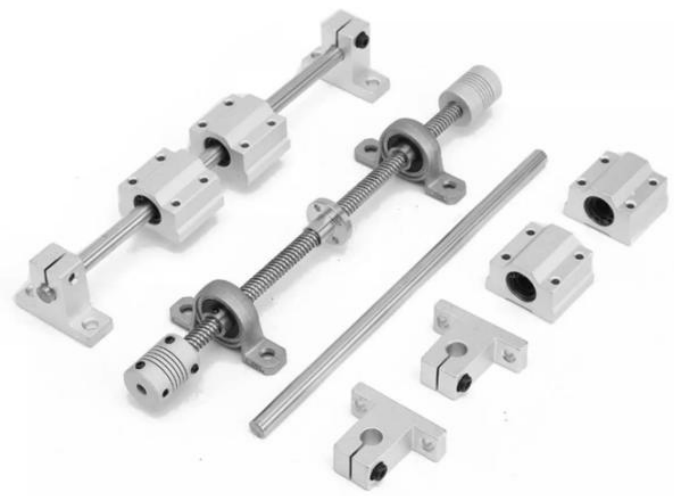

Fig. 5: $16 \mathrm{~mm}$ stainless steel linear guide rail support and computer numerical control components

\section{G. Moving Mechanism}

The main structure of the latex glove cutting system is used computer numerical control (CNC) design mechanism. This mechanism has widely used this machines which allow the machine to have 4 degrees of freedom: $\mathrm{x}, \mathrm{y}, \mathrm{z}$ and rotating actuator axis movement. The $\mathrm{Y}$-axis movement mechanism is shown in Fig. 6.

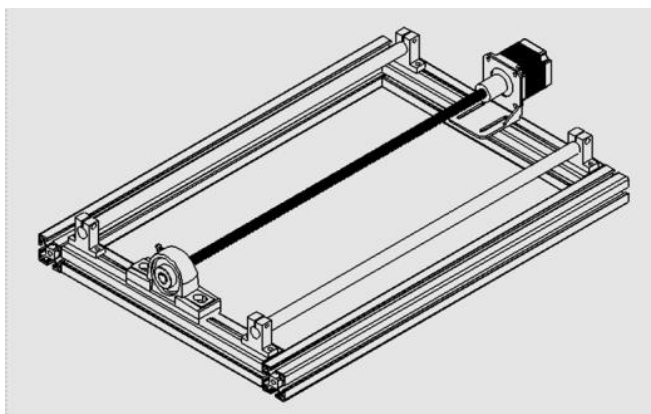

Fig. 6: $y$-axis movement design of latex glove samples cutting system

\section{H. Samples Positions}

For Bradford reagent protein test, 7 pieces of samples with size $2 \mathrm{~cm}$ by $2 \mathrm{~cm}$ are selected. These samples positions are thumb, index finger, middle finger, ring finger, pinky and 2 on palm [11]. The reasons for choosing these positions are:

a) Dipping Process in glove manufacture, most proteins remained on the fingertip.

b) Most touching area for users, especially caregiver and medical surgery doctor.

c) Ease the samples image scanning process.

d) Standard size samples for Bradford reagent protein test

The position of the glove sample selection is shown in Fig. 7.

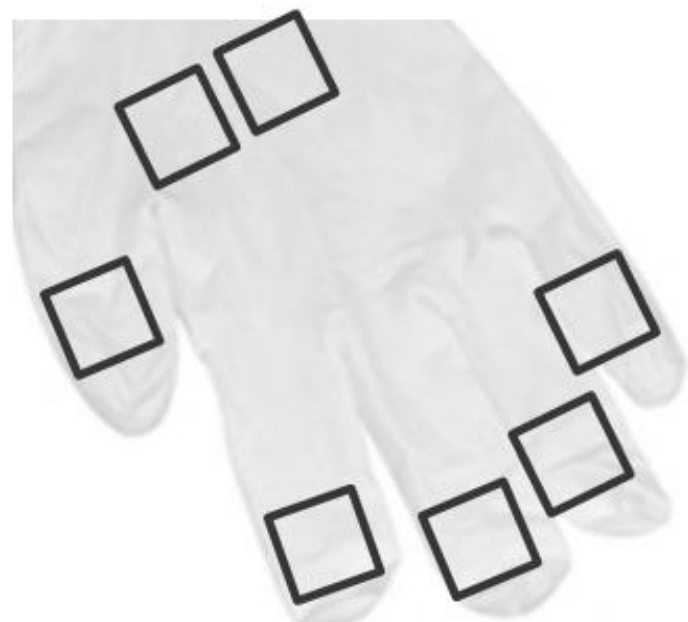

Fig. 7: The samples position with dimension $2 \mathrm{~cm}$ by 2 cm sizes 


\section{CUTTING FORCE CALCULATIONS FOR LATEX GLOVE (TONNAGE)}

The formula [12] of cutting force for $20 \mathrm{~mm}$ by $20 \mathrm{~mm}$ latex glove samples shows as below:

$$
\text { CuttingForce }\left(f_{C}\right)=L \times S \times T_{\max }
$$

$L=$ Sample one side length to be cut in millimeter (mm)

$S=$ Sheet thickness in millimeter $(\mathrm{mm})$

Tmax $=$ Shear strength $\left(\mathrm{N} / \mathrm{mm}^{2}\right)$

The table below shows the shear strength of the materials including latex glove.

Table II: Shear strength of different materials [2]

\begin{tabular}{|l|l|}
\hline Material & T $\max \left(\mathbf{N} / \mathbf{m m}^{2}\right)$ \\
\hline Steel with 0.1\% carbon & $240-300$ \\
\hline Steel with 0.2\% carbon content & $320-4000$ \\
\hline (deep draw steel) & $360-420$ \\
\hline Steel with 0.9\% carbon & $450-550$ \\
\hline Silicon Steel & $350-450$ \\
\hline Stainless Steel & $200-400$ \\
\hline Copper & $350-400$ \\
\hline Brass & $360-450$ \\
\hline Bronze & $300-20$ \\
\hline German silver (2- 20\% Ni, 45- 75\% & $30-40$ \\
Cu) & \\
\hline Tin & $100-120$ \\
\hline Zinc & $20-30$ \\
\hline Lead & $20-120$ \\
\hline Aluminum 99\% Pure & $150-320$ \\
\hline Aluminium manganese alloy & $120-250$ \\
\hline Aluminium silicon alloy & $20-50$ \\
\hline Paper \& card board & $70-90$ \\
\hline Laminated paper & $90-120$ \\
\hline Laminated fabrics & $50-20$ \\
\hline Mica & $20-40$ \\
\hline Plywood & 7 \\
\hline Leather & $48-90$ \\
\hline Soft rubber & $20-60$ \\
\hline Hard rubber & $40-60$ \\
\hline Latex Glove & $14-18$ \\
\hline & \\
\hline
\end{tabular}

A. Calculation of Press Capacity

$f_{P}=f_{C}+f_{S}$

$f_{P}=$ Press Force

$f_{C}=$ Cutting Force

$f_{S}=$ Stripping Force

As, $f_{S}=10 \%$ to $20 \%$ of $f_{C}$

Material: Latex Glove

Sheet thickness $(S)=0.08 \mathrm{~mm}$

Blank Size $=20 \mathrm{~mm} \times 20 \mathrm{~mm}$

$L=80 \mathrm{~mm}$

$\operatorname{Tmax}=18 \mathrm{~N} / \mathrm{mm}^{2}$
$f_{C}=L \times S \times T_{\max }$

$=20 \times 0.08 \times 18$

$=28.8 \mathrm{~N}$

$=288 \mathrm{~kg} f$

$=0.288$ Ton

$f_{P}=f_{C}+f_{S}$

$=28.8+20 \% 28.8$

$=51.84 \mathrm{~N}$

$=518.4 \mathrm{kgf}$

$=0.5184$ Ton

Press Capacity $=0.5$ Tonnage

\section{COMPUTER NUMERICAL CONTROL MOVING MECHANISM CALCULATION}

The formula [13] and calculation for the moving step of the automated system are shown as below:

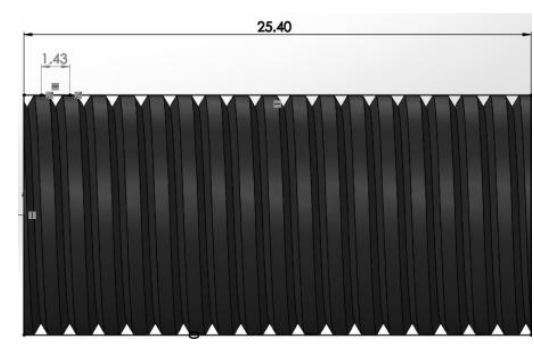

Motor Step $=200$ Steps per Revolution

Turns or Threads per inch $=18$

Lead Screw Pitch $=0.056$ inches

Number of Starts $=1$

Microstep $=1$ (Full Step)

$\frac{\text { Steps }}{\text { Inch }}=\frac{\text { Threads }}{\text { Inch }} \times \frac{1}{\frac{1}{\text { Microstep }}} \times$ MotorStep

$=18 \times 1 \times 200$

$=3,600 \frac{\text { Steps }}{\text { Inch }}$

Microstep $=\frac{1}{2}$ (Half Step)

$\frac{\text { Steps }}{\text { Inch }}=7,200$

Microstep $=\frac{1}{4}($ Quad Step $)$

$\frac{\text { Steps }}{\text { Inch }}=14,400$ 
Compare the calculation result; with the micro-step equal to 1 , the stepper motor rotating faster, fewer steps take in order to travel an inch distance.

\section{MANUFACTURING CONSIDERATION IN DEVELOPMENT OF LATEX GLOVE SAMPLES CUTTING SYSTEM}

Manufacturing research reveals the parameters that can be most effectively affected to increase yield and improve accuracy. The process [14] of advanced engineering manufacture involved the concepts that show as below: Process planning, Computer Numerical Control (CNC) and Cutting tools.

\section{A. Production Process}

That is 4 types of production:

1) Job/ Unit Production

2) Batch Production

3) Mass Production

4) Continuous Production

\section{B. Classification of Manufacturing Processes}

\section{1) Primary Shaping Process}

Parts produced through these processes may or may not be needed. Some important major shaping processes will ongoing further actions. Those processes are:
a) Plastic Technology
b) Bending
c) Gas Cutting

\section{2) Secondary Machining Processes}

These processes are required for fabrication of latex glove samples cutting system. The pre-process of finishing are:
a) Turning
b) Threading
c) Milling
d) Drilling
e) Slotting

After the materials undergo the pre-process, some surface finishing processes are required. The process will affect the change of properties of the machine, the smooth process must be performed for every material that already undergoes pre-process. This smoothing process as the finishing process of the preparation of the materials.

\section{3) Machine Tools}

The machine tools below are required and used for latex glove samples cutting system with rotary cutter mechanism as per the conceptual design:
a) Turning Machine
b) Milling Machine
c) Drilling Machine
d) Surface Grinder

\section{4) Process Sequence}

The manufacturing process chosen must be an economic balance of materials, manpower, product design, tools and equipment, plant space, and many other factors that affect cost and utility.

In the order of the process, all of the above factors must be considered, providing quality products.

\section{Raw Material Form}

1) Cylindrical (Shaft, cutter holder)

2) Plate (Bakelite plate, aluminium plate)

Process Sequence Plan for Plate form Raw Material

Table III: Process Sequence Plan for Plate form Raw Material

\begin{tabular}{|c|c|}
\hline Process Sequence Plan & Tools Involved \\
\hline Sizing & Milling Machine \\
\hline Tolerance & Surface Grinder \\
\hline $\begin{array}{c}\text { Drill Hole for screw and } \\
\text { positioning }\end{array}$ & Drilling Machine \\
\hline Drilled holes tapping & Thread Tap \\
\hline
\end{tabular}

E. Process Sequence Plan for Cylindrical form Raw Material

Table IV: Process Sequence Plan for Plate form Raw Material

\begin{tabular}{|c|c|}
\hline Process Sequence Plan & Tools Involved \\
\hline Sizing & Turning Machine \\
\hline Cylindrical Griding & Drilling Machine \\
\hline $\begin{array}{c}\text { Drill Hole for screw and } \\
\text { positioning }\end{array}$ & Thread Tap \\
\hline Drilled holes tapping &
\end{tabular}

\section{RESULTS AND DISCUSSIONS}

For samples cutter system for latex glove able to cut the samples into a dimension of $20 \mathrm{~mm}$ by $20 \mathrm{~mm}$ and $0.08 \mathrm{~mm}$ thickness with a $28 \mathrm{~mm}$ diameter rotary cutter designed.

The latex glove samples cutting system with rotary cutter mechanisms able to retrieve 7 samples from a latex glove at once. The time taken for the cutting process around 5 minutes, which is shorter compare to manually cut by human and the protein concentration test with Bradford reagent can be more efficient on latex glove manufacture quality control.

The performance of an engineered component is limited by the nature of the material being fabricated and the shape in which it can be formed. In some cases, the material can be satisfactorily selected by specifying the range of individual attributes. More commonly, the performance depends on the combination of properties and the suitable material is selected by maximizing one or more "performance indices."

\section{CONCLUSION}

Cutting machines that are available in the market are unable to cut the latex glove into several pieces of samples with certain sizes. Most of them operate manually not automatic, having larger cycle time. Hence more manpower is required and is not economical. In order to overcome these problems, latex glove samples cutting system with rotary cutter mechanism is fully automatic developed, with just need an operator with limited training to place the latex glove on input and press the start button. The cutting system 


\section{LATEX GLOVE SAMPLES CUTTING SYSTEM WITH ROTARY CUTTER MECHANISM}

is designed and can be fabricated with minimum cost by considering the proper process, proper materials selection, proper structure design, stepper motor selection and microcontroller selection. Therefore, the cutting system can increase the production rate in glove manufacture, reduce cycle time, less skill operator required and reduce manpower.

\section{REFERENCES}

1. A. University, "How Disposable Latex Gloves are Made," pp. $1-8,2009$.

2. M. Taghizadeh-Behbahani, B. Hemmateenejad, and M. Shamsipur, "Colorimetric determination of acidity constant using a paper-based microfluidic analytical device," Chem. Pap., vol. 72, no. 5, pp. 1239-1247, 2018.

3. T. Yagami, M. Sato, and A. Nakamura, [Colorimetric determination of the total protein eluted from latex gloves] 1993.

4. R. V. Nouroozi, M. V. Nouroozi, and M. Ahmadizadeh, "Determination of Protein Concentration Using Bradford Microplate Protein Quantification Assay," Int. Electron. J. Med., vol. 4, no. 1, pp. 11-17, 2015.

5. J. D. Easterbrook, T. Shields, S. L. Klein, and G. E. Glass, "Smartphone for Point-of-Care Quantification of Protein by Bradford Assay Camila," J. Braz. Chem. Soc, vol. 22, no. 12, pp. 2396-2402, 2011.

6. D. Thinking, "Material Selection with Flowcharts, Phases in Design, Spring back, Design Thinking," 2019.

7. P. Borlepwar, "Development of Automated Leather Cutting Machine," Int. J. Mod. Trends Eng. Res., vol. 3, no. 8, pp. 236-242, 216.0

8. W. Are and K. Bevels, "Understanding Single and Double Bevel Knives," 2019. [Online]. Available: https://kamikoto.com/blogs/fundamentals/understandingsingle-and-double-bevel-knives.

9. A. Considerations, “(800) 819-8900,” 2019.

10. Anonymous, "Advantages of Using Aluminium Cookware," Green B., vol. 44, no. 0, pp. 1-2, 2012.

11. Bradford, P. Description, A. F. Used, and C. Number, "Bradford Reagent protocol sigma.pdf," pp. 3-8.

12. M. P. Madan, "Cutting force calculation in sheet metal Blanking \& Piercing," 2016.

13. GreigRS, "Stepper motors and drives, what is full step, half step and microstepping?," 2015. [Online]. Available: https://www.rs-online.com/designspark/stepper-motors-anddrives-what-is-full-step-half-step-and-microstepping.

14. P. Contents, "1 ) Unit or Job type of production," 2019.

15. C. L. Packham, "Latex Gloves," Occup. Med. (Chic. Ill)., vol. 49, no. 4, pp. 267-268, 2007.

16. C. P. Tso, H. Y. Ting, C. S. Ong, K. S. Sim, "Latex Glove Protein Detection Using Maximum-Minimum Clustering Variation Technique," 2011, vol. 35, no. April 2017.

17. Rodney C., W. E. Webler, and R. Von Oepen, "LASER CUTTING SYSTEM," 2013.

18. Y. Shu, "Gel Cutter For Recovering DNA, RNA and Protein From Agarose Gel and poly-Acrylamide Gel," 2005.

19. W. Martell, "Paper Cutting Mechanism," 2015.

20. A. Hrishikesh Tavanandi, S. Deepak, K. Venkateshmurthy, and K. S. M. S. Raghavarao, "Development of a lemon cutting machine," in Journal of Food Science and Technology, 2014, vol. 51, no. 12, pp. 3846-3853.

21. "Robust Latex Glove Cutting Machine and Protein Estimation System," p. 2014, 2014.

22. Brian Reed, "Advantages of CNC over Conventional," Fairlawn Tool Inc., 2016. [Online]. Available: https://www.fairlawntool.com/blog/advantages-cnc-machines/

23. Bradford protein assay. Rice University website 2012 [cited 2015 August 10]; Available from: URL: http://www.ruf.rice.edu/ bioslabs/methods/protein/bradford.ht $\mathrm{ml}$.

24. Thermo scientific pierce coomassie (Bradford) protein assay. Fisher scientific website 2015 [cited 2015 August 10]; Available from: URL: https://www.fishersci.com/shop/products/thermoscientificpierce-coomassie-bradford-protein-assay/p-3827564

25. Walker JM. The protein protocols handbook. 2nd ed. New Jersey: Humana Press; 2002:15-21.

26. Bradford protein assay: Calculation of an unknown standard. G-biosciences website 2014 [cited 2015 August 10]; Available from: URL: http://info.gbiosciences.com/blog/bid/164578/BradfordProtein-Assay-Calculation-of-An-Unknown-Standard.

27. B. Witkowski et al., "Analysis of latex protein content by liquid chromatography coupled with tandem mass spectrometry (HPLC/MS/MS)," Anal. Methods, vol. 7, no. 24 pp. 10376-10384, Dec. 2015. 